\title{
Mafia Women: A Study on Language and Mental Representations of Women Engaged with Mafia Members
}

\author{
Adriano Schimmenti ${ }^{1{ }^{*}}$, Serena Giunta ${ }^{2}$ and Girolamo Lo Verso ${ }^{2}$ \\ ${ }^{1}$ Faculty of Human and Social Sciences, UKE - Kore University of Enna, Italy \\ ${ }^{2}$ Department of Psychology, University of Palermo, Italy
}

\begin{abstract}
For a long time, women in the Mafia were considered victims who were unaware of the activities of the men in their families. However, it has recently been demonstrated that these women may play an important role in the organisation, particularly in the transmission of Mafia values. In this study, we explored the representations of self, relationships, and the Mafia world in women engaged with Mafia members. This was done by means of in-depth interviews and computer-assisted text analysis. A cluster analysis was applied to words used by the women in the interviews. Three clusters emerged that accounted for $85 \%$ of the principal contents of the interviews. These were interpreted as "representations of family", "representations of social relationships", and "ideals and values". The analysis of words included in each cluster suggested that Mafia women are deeply involved in the transmission of traditional Sicilian values to their offspring. These ideals and beliefs are deeply rooted in the Mafia organisation and they involve attributing a central role to family, religion, and honor within the Mafia culture. Findings of the study could be positively used for developing appropriate preventative and social measures that may help these women change their ideals and beliefs related to the Mafia world, thus breaking the transmission of Mafia values.
\end{abstract}

Keywords: Mafia, criminal organisations, women, mental representations, qualitative analysis.

The original Mafia (whose traditional Sicilian name is Cosa Nostra) emerged in Sicily in the middle of the nineteenth century as an association of criminal groups, known as "families", that shared a common organisational structure, values and code of conduct (Lupo 2009).

Family is a key word to understanding the Mafia. Family is the name of the organisation's cells: in the Mafia world, cities are subdivided into several districts according to these cells (i.e. the families) that have "jurisdictional" powers and rights to them. When an individual joins the Mafia family, he or she can never leave it. In fact, the Mafia offers a symbolic pact to the individuals: the family will give them protection and safety, but they must be obedient, loyal, and trustworthy (Lo Verso and Lo Coco 2004).

For a long time, a woman in a Mafia family was considered having a subordinate and dependent status. Society imagined Mafia women as victims who were unaware of the activities of the men in the families. Until the nineties of the past century, many scholars considered the Mafia an organisation based on "absolute masculinity" (Falcone 1992), a hidden world whose access was granted only to individuals who were able to prove a masculine strength and will. This belief was partially rooted in the Mafia's sexist

*Address correspondence to this author at Faculty of Human and Social Sciences, UKE - Kore University of Enna, Italy; Tel: 00393286267944 ;

E-mail: adriano.schimmenti@unikore.it ideology (Di Maria and Lo Verso 2007; Flocca and Giunta 2003), which was extended to its wider social fabric of criminals, and which was unable to recognise the important role women actually played in the transmission of Mafia values. The outdated description of Mafia women given by Tommaso Buscetta, for example, was that of a wife who is the "toy-model of her husband" (Dino 2007): a woman who does not speak and who does not think because she is trained to keep quiet and remain in the well-defined world of domestic life (Siebert 1996).

Recent studies on the Mafia from psychological and sociological and perspectives (e.g. Cottino 1999; Di Maria and Lo Verso 2007; Dino 2007; Fiore 1997; Giunta, Licari, and Lo Verso 2004; Lo Verso 1998; Lo Verso et al. 1999) have suggested that this description does not fit well with the role played by women in the Mafia. The research done on Mafia members' children and wives who asked for psychotherapy as well as the interviews with judges who have worked on prosecutions and trials involving members of Cosa Nostra, allowed society to understand to a higher degree the Mafia organisation and the mental functioning of its members (Lo Verso and Lo Coco 2004). These studies showed that these women are often well-integrated in the Mafia world, and at the same time many of them play an integral role in the organisation, being the unofficial transmitter of Mafia culture, values, ideals, and beliefs (Di Maria and Lo Verso 2007; Fabj 1998). 
Thus Mafia women may represent the most mysterious secret of this "masculine" criminal world. Their role within the Mafia became more evident when the "emergenza pentiti" (i.e. "the informants' emergency") weakened the organisation by revealing relevant information (Schneider and Schneider 2003). This occurred after the Maxi Trial held in Palermo between 1986 and 1987, where the Sicilian prosecutors indicted 475 mafiosi for a multitude of crimes relating to Mafia activities, based primarily on testimonies given as evidence by former Mafia bosses turned informants, known as pentiti. In those years, the Mafia relied on their women to openly defend the honor of their beloved husbands, sons, or brothers, or even to disown them. In fact, some of these women publicly declared that they did not approve the behaviour of collaborators of justice, calling them infami (i.e. infamous) because the informants were ruining the families' or organisation's reputation with their words. Other women whose relatives were likely to become informants publicly denied that their beloved ones would ever become infami. A small part of these women endorsed the behaviour of their relatives, saying that breaking the Mafia's code of conduct and thus deciding to become pentiti was in response to the use of violence by other Mafia families towards people who were usually not included as targets in the traditional Mafia values, such as children and women. It is possible that these women did not act in such a way, outside and against the constraints of their traditional social role, only for the sake of convenience, such as the fear of retaliation and revenge (Dino 2007; Siebert 1996). They likely did so because their unofficial but critical role in the Mafia was that of interpreter and transmitter of the Mafia's internalised codes. In light of these observations, some scholars have considered the role of women within the Mafia organisation as the "underground watchtower" (Lo Verso 1998). Studies have shown that many Mafia women were aware of the criminal activities of their relatives, and that they were also aware of their role in the organisation, as reported by the informant Leonardo Messina: "Women cannot be affiliated - and they will never be - in Cosa Nostra, but they have always played a key role. Men like me have to marry the right woman, a daughter of a man like myself. Cosa Nostra has controlled women since their childhood, as it has done with the men. So the best asset a man of honor can have is a woman who is aware of her role" (Principato and Dino 1997: 74).

Moreover, on a symbolic level, it must be noted that the Mafia world implicitly recognises the role of women as the guardians and transmitters of its cultural code. In fact, when the members refer to the organisation or any of its parts, they always use nouns in the feminine gender: terms such as "Mafia", "Cosa Nostra", "family"; "the Dome", are all feminine words in the Italian language. Moreover, within the Mafia family structure even the boss is represented as a highly powerful mother, being called the mammasantissima (i.e. the most sainted Mother), who educates, controls and supervises the work of her offspring (the picciotti, i.e. the boys).

As in many other social environments, even within the Mafia organisation the women have the task of setting the foundation for the development of their children's identities. Therefore, the mothers will transmit the implicit social models of the organisation: thus they will push their sons to continue their fathers' criminal activities in order to become real men of honor, and their daughters to become perfect Mafia women and mothers (Fiore 1997). Again quoting Leonardo Messina: "We want our children to grow up in the environment of Cosa Nostra. We believe it is right that our daughters marry a man of honor. The woman must essentially convey the thoughts of her father" (Principato and Dino 1997: 116).

However, the identity of Mafia women could be challenged today as a result of critical changes internal to the Mafia organisation and the global world as well (Roth 2010). For instance, in the last ten years an effective police activity allowed to arrest many picciotti and even Dons in Sicily (e.g. in 2006 the boss Bernando Provenzano was arrested). Thus, many Mafia women today are forced to take on responsibilities and make decisions for the family following their husbands' imprisonment, death, or decision to collaborate with the law.

In light of the aforementioned considerations, we conducted in-depth interviews with five women belonging to the Mafia and we analysed their responses in order to explore their mental representations of self, the social world, and the Mafia culture.

\section{METHOD}

\section{Participants}

Five women belonging to the Mafia were interviewed. They were aged between 38 and 54 (mean age $=44 ; S D=3$ ) and all of them lived in Sicily. 
Four of these women were wives of Mafia members and one was the lover of a Don. Specifically, the Mafia members included a fugitive, a collaborator of justice, one on probation, and two who had been killed by former Mafia accomplices.

\section{Procedures}

An institutional agreement between the Chair of Psychotherapy at the University of Palermo and the Court of Palermo had been made to ethically clear the research. Initially, a draft of a semistructured interview on mental representations of Mafia members was developed by the third author, who has almost thirty years of experience in psychological research on the Mafia. Expert input to improve the interview development was given by a number of other researchers who have studied issues relating to the Mafia in the psychological, criminological, legal, sociological, and anthropological fields, thus resulting in the final version of the interview.

Participation in the interviews had been requested for ten years (2002-2012) to more than 100 people involved with the Mafia, including convicted offenders, collaborators of justice, people investigated or prosecuted for Mafia-related crimes and even relatives of Mafia members who asked for psychological assessment, resulting in less than $5 \%$ of women willing to cooperate. Therefore, the reduced number of participants was due to the difficulty of tracing people belonging to Cosa Nostra who were willing to cooperate in psychological research.

All the participants were introduced to the aim of the study. The researchers explained that data would be recorded according to a strict procedure to guarantee the confidentiality of information, with personal information kept anonymous by the substitution of the participants' names with a random code. Participants were also told that they had the right to withdraw from the study at any time. Interviews were administered individually by experienced and highly trained clinical psychologists in a research office. Interviews lasted from about one hour to almost three hours, depending on the participants' style of communication.

\section{Measure}

The Psychological Assessment of Mafia Members Women Version (PAMM-WV; Lo Verso 2003) is a semi-structured clinical interview which aims to investigate six broad areas in the lives of women involved with the Mafia. This is the only interview specifically developed for assessing psychological characteristics of individuals belonging to Mafia organisations, and it includes 78 questions regarding: (1) Family life (e.g., [if the interviewee has children] How is your relationship with your children?); (2) Personal History (e.g., Do you remember as a child whether you felt that in your family there were secrets that you should not know?); (3) General Values and Beliefs (e.g., What do you think about divorce?); (4) Internalized Mafia Values (e.g., [if the interviewee comes from Sicily?] What do you think about the dialectal proverb "Nenti sacciu e nenti vogghiu sapiri" [I do not know anything and I don't want to know anything]?); (5) Psychopathology (e.g., Do you have problems falling asleep?); (6) Relationship with the Justice System (e.g., What do you think about informants and collaborators of justice?). The analysis of the answers allows for an assessment of the Mafia member's mental representations of self, the social world, and the Mafia culture. It has been proposed that the PAMM-WV interview can be analysed both quantitatively and qualitatively, with interviewers applying scores on the six domains and qualitatively analysing the emerging representational themes concerning self, relationships and the Mafia world. However, given the current state of research regarding this measure, which is in its infancy, as well as the small sample size in the present study which does not allow for the application of proper methods to test the psychometric properties of the scores obtained in the six domains, only an explorative qualitative analysis of the transcripts is presented here, supported by results from computer-assisted text analysis.

\section{Data Analysis}

All the interviewees' answers were transcribed and analysed qualitatively and quantitatively with the help of computer software used for text analysis. The computer-assisted analysis on transcripts was performed using the 'T-LAB' (Lancia 2004). The T-LAB is a software that includes a combination of linguistic and statistical tools to be applied in text analysis. It carries out different types of analyses, including quantitative analyses (in terms of occurrence, cooccurrence, and association of words in different sets of text), and the possibility to categorise specified units of analysis in the texts to examine their mutual relationships. In particular, the analysis of lexical units allows the classification of words inside a text through the use of keywords: this can be done automatically, according to linguistic criteria (lemmatization), or by 
applying a specific dictionary or semantic grid that was previously defined by researchers. In this way, the T$L A B$ provides researchers with useful information such as associations between words, comparisons between pairs of keywords, correspondence analysis and clustering of words.

In this study, we applied the automatic procedure for classifying keywords, which includes the selection of words above the threshold of occurrence in the interviewees' transcripts and the application of a chisquare test to select the words that "make the difference", i.e. those words with the largest chi-square values among the five interview transcripts. This procedure allowed us to extract the elementary contexts of the discourse, i.e. the sentences or associations of sentences that result central for the understanding of the linguistic organisation of the discourse among the different interviews. Based on these elementary contexts we conducted a cluster analysis, a method that allows for the grouping of keywords into clusters, based on the interviewees' use of them (Lancia 2012).

\section{RESULTS}

The computer-assisted text analysis generated three interpretable clusters that accounted for $85.13 \%$ of the elementary contexts in the interviews. Cluster 1 , which accounted for $29.39 \%$ of the elementary contexts in the transcripts, included keywords such as "family", "relationships", "daughter", "mother, "love", "home", and was subsequently interpreted as "the representation of family" cluster; Cluster 2, which accounted for $29.05 \%$ of elementary contexts in the transcripts, included words such as "suffering", "school", "to go out", "jail", "newspaper", and was therefore interpreted as "the representation of social relationships" cluster; Cluster 3 , which accounted for $26.69 \%$ of elementary contexts in the transcripts, included words such as "life", "God", "man", "wrong", and was interpreted as "the ideals and values" cluster. Table 1 summarises the results of this analysis.

Results of the cluster analysis on the elementary contexts of the interviews were reflected in the qualitative analysis of the full transcripts. It emerged that the women were prone to idealize the family environment, including the family where they grew up, and tended to transmit traditional values toward their children. For example, the wife of a murdered Mafia member said about her sons: "I have three sons who are all married: two of them live in Sicily, and the other with his own family in Germany. And they have lived as I've educated them, with strong values and no common-law marriages before matrimony: they are well-educated. They have been educated by me like l'd been educated by my mom. They are very good boys." Another participant, the wife of a collaborator of justice, said: "My daughter wanted to do her own thing, and she was a rebel when she was an adolescent, but now she has learned how to behave. We have a beautiful relationship; we are very tight, almost like sisters." The family world was conceived as a world of female relationships and interactions, where the only representative masculine figures were those considered to be strong supporting figures in the traditional Sicilian culture: in fact, the only male figures that appeared in Cluster 1 were the grandfather, who traditionally has the role of teaching children about life, and the boyfriend, who is considered in the Sicilian tradition the one who has to support the daughter and to take responsibility for her emotional well-being.

This was mirrored by the women's selfrepresentations as "good Christians", as it emerged in interviews and is reflected in Cluster 3 of the computerassisted text analysis, where the word "God" resulted in associations with other words such as "to know", "life", and "wrong", which could testify to a moral sensibility and standard for internal values based on the traditional Catholic religion. For example, one of the women said: "I am Catholic, and I am very close to the sacraments, I always pray. God always helps me, although I had some difficult periods when my faith seemed to disappear. The Catholic religion is an important part of my life, every day I am close to the Lord. God always helps me, I can feel it inside."

The latter result was in contrast to the women's representations of the social world, one that is masculine and intimidating. A polarity emerged between family relationships, perceived as positive and protective, and the relationship with the external society, perceived as threatening and disturbing. The words included in the second cluster could indeed suggest that the participants are concerned about justice and experience suffering for the prosecution of their partners. The newspapers with their reports, the school, the jail, all clearly refer to the impact of the social world, which is recognised as judgmental, adverse and causing a life of suffering. A woman whose partner was on probation reported an episode: "It is something I cannot tolerate. A teacher at school read the news of my husband in front of the class. Why the need for this type of humiliation? My daughter 
Table 1: Results of the Cluster Analysis on the Words Used by Mafia Women in the Interviews

\begin{tabular}{|c|c|c|c|}
\hline & Total Occurrences in Transcripts & Occurrences within the Cluster & Chi-Square \\
\hline \multicolumn{4}{|l|}{ Cluster One } \\
\hline Problems & 31 & 19 & 16.98 *** \\
\hline Family & 31 & 20 & $5.21 *$ \\
\hline Relationships & 20 & 14 & $17.04^{* * *}$ \\
\hline Sister & 16 & 13 & $21.98 * * *$ \\
\hline Wedding & 16 & 11 & $12.63^{* * *}$ \\
\hline Daughter & 15 & 5 & 6.02 * \\
\hline Mother & 11 & 8 & $6.78^{* *}$ \\
\hline Grandfather & 6 & 6 & $14.71^{* * *}$ \\
\hline Love & 6 & 5 & 8.59 ** \\
\hline Boyfriend & 5 & 4 & 6.28 * \\
\hline Home & 5 & 4 & 6.28 * \\
\hline \multicolumn{4}{|l|}{ Cluster Two } \\
\hline Suffering & 46 & 7 & 4.06 * \\
\hline Memory & 16 & 10 & $9.18^{* *}$ \\
\hline To say & 15 & 13 & $25.44^{* * *}$ \\
\hline School & 13 & 7 & 4.06 * \\
\hline To go out & 12 & 10 & 5.48 * \\
\hline Dad & 9 & 9 & $22.67^{* \star *}$ \\
\hline Environment & 9 & 7 & 10.69 ** \\
\hline Jail & 8 & 6 & $8.42^{* *}$ \\
\hline Newspaper & 6 & 6 & $14.95^{* * *}$ \\
\hline \multicolumn{4}{|l|}{ Cluster Three } \\
\hline Life & 31 & 11 & 10.99 *** \\
\hline God & 25 & 18 & $5.87^{*}$ \\
\hline To find & 21 & 7 & $7.63^{* *}$ \\
\hline Period & 14 & 6 & 5.32 * \\
\hline Man & 12 & 9 & 26.99 ** \\
\hline To know & 11 & 5 & $7.97^{* *}$ \\
\hline Wrong & 6 & 6 & $10.04^{* *}$ \\
\hline
\end{tabular}

Note: Statistical significance of the word within the cluster ${ }^{*} p<.05 ;{ }^{* *} p<.01 ;{ }^{* * \star} p<.01$.

asked him not to read it, but he did anyway. I said just ignore it, what else can I say? My daughter has been kicked out from school this year. She said to her teacher, "Because you read the news about my dad, I won't do my schoolwork anymore."

There were also many excerpts where the women minimized, endorsed, or supported their partners' behaviour. For example, the wife of a fugitive said: "The Mafia was not this way twenty years ago. Moreover, the justice system tends to define too many individuals as mafiosi, exactly in the same way it defines everyone who acts against the Italian unfair laws and social injustice as a gangster or a criminal. I suffered, I was sad and concerned for my children". This is mirrored in the grouping of some words into the third cluster, where the words "God", "to know", and "life" were also associated with the word "man". Some excerpts clearly suggest the idealization of the man of honor. The lover of a Mafia member said: "He was very sweet with me, he gave me everything I asked for, I was always satisfied. He was a man respected by 
everyone, everything was available to me when I was with him. I was like a queen. His presence in my life was the only beautiful thing I had on my mind. We were good together, he adored me. He was a beautiful man, I loved him, I felt it inside me. He never hurt me, everything was beautiful. And I was proud that everyone respected me. When I was his lover, I think people envied my position. Other women tried to take my place, other women envied my role and position."

Finally, it is to be highlighted that there were no words in the cluster analysis that directly referred to Mafia crimes. In fact, none of these women talked about their partners' crimes, although all of them were aware of the reasons why their partners had been prosecuted or killed.

\section{DISCUSSION}

This study aimed to explore the mental representations of self, relationships, and the Mafia world among women associated with Mafia members. To the best of our knowledge, this is one of the first study that has empirically addressed psychological dimensions in Mafia women, and the first ever that has attempted to explore their mental representations.

The study on women's mental representations was performed by means of computer-assisted text analysis, with linguistic research on central properties of discourse and their modifiers in sentences providing strong theoretical support for its use (Hampton, Passanisi, and Jönsson, 2011; Harris 2002). The cluster analysis on the keywords selected for their higher occurrences in the interviews generated three interpretable clusters of words that accounted for about $85 \%$ of the elementary contexts in the transcripts.

Results of a computer-assisted text analysis strongly support the assumption that women play a crucial role in the Mafia world. In particular, the findings of the study suggest that Mafia women are the owners and transmitters of traditional Mafia values related to family, which may include rules of behaviour, code of conduct, religious beliefs, as well as overprotection in caregiving that may also imply total support and even endorsement of maladaptive behaviours in the family.

The first cluster primarily included words related to the emotional world of the women, particularly their feelings about family. The cluster analysis therefore suggests that family life represented the core aspect of the women's identity. Mafia women tended to represent themselves principally as mothers who have the role of educating their children and teaching them the traditional code of conduct and behaviours of the Sicilian people (Di Maria and Lo Verso 2007; Dino 2007; Principato and Dino 2007).

On the contrary, the second cluster included words that describe the daily life of a woman who is involved with the Mafia. Words in this cluster suggest that a deep psychic suffering may be involved in the women's relationship with the social world, revolving around negative affects and themes such as shame and pride. Notably, feelings of shame have been posited in psychological literature as an organiser of the individual's relationship with the social world (Schimmenti 2012), especially among women (Passanisi, Leanza and Leanza 2013). At the same time, shame is a crucial anthropological dimension in the traditional Sicilian culture, because the external image of a family and its apparent wealthy and perfectionism is an indicator of the quality of its members (Di Maria 1997; Fiore 1997). Therefore, the absence of the father figure (because he is incarcerated, a fugitive, or has been killed) may result in severe problems with respect to the women's relationship with the social world: in their mental representations, the social world, and especially the justice system, is often perceived as threatening and unfair. This could result from the feeling of shame brought on by the absence of their partner which they have to justify not only to their children, but even to the other individuals and families in their society. This condition, in turn, frequently leads to feelings of loneliness and helplessness in the women.

The third cluster included words that reflect the ideals and values of the women. A strong sense of religiosity emerged, which contrasted with the behaviours of their partners, which were often idealized despite their criminality. It was as if these women split their internal values and moral standards into all goodall bad representations, based on faith and the principles of the Gospel, while at the same time they compartmentalised their knowledge about their partner's crimes, being unable to recognise that their partners behaved immorally according to the same principles. Religion is a sort of lifeline for these women, rescuing them from conflicts and preventing the emergence of guilt. This likely does not apply only to women. Incidentally, compartmentalisation could be considered as an important psychological dimension in Mafia culture. For example, compartmentalisation could explain why many Mafiosi show lower rather than higher psychopathic traits, demonstrating positive care 
toward the family while they are able to commit ignominious crimes (Schimmenti et al. 2014). Compartmentalisation might be expressed even in the form of religious compartmentalisation (Giunta, Licari and Lo Verso 2004; Lo Verso 1998; Lo Verso et al. 1999): in fact, many Dons, including brutal godfathers such as Bernardo Provenzano, declared that they strongly believed in God and in the Gospel, and often their home was full of holy pictures and statues representing Mother Mary. However, compartmentalisation may play an even more important role in the mental functioning of Mafia women, given that the words "Mafia" and "crime" as well as their derivates appeared in less than five sentences in the transcripts and therefore were not included in the cluster analysis. It is possible that during the interviews, and perhaps even in their daily lives, Mafia women tried to distance these words from their internal experiences, as they are cause of psychic pain and severe distress.

The present study has a number of limitations that need to be addressed. First of all, this is an exploratory study, with a significantly small sample size selected in a very unusual way, therefore its results cannot generalise to the population of women associated with Mafia members. Second, the study investigated only women who were engaged with members of the original Mafia (Cosa Nostra), and in other cultural contexts the mental representations of women engaged with people who operate in Mafia-style organised structures would likely emerge as very different, influenced by the specific culture and its implicit social and anthropological values (Dean, Fahsing, and Gottschalk 2010; Nicaso and Lamothe 2005). Third, the use of computer-assisted text analysis to help individuate and describe mental processes, although largely used in the psychological, sociological and criminological field, is at best only tentative, as it is every attempt to measure complex dimensions of the individual's way of functioning. However, this study also has a number of strengths, including the complexity of the investigated construct, the in-depth analysis of interviews with individuals who usually do not participate in research, and the attempt, perhaps for the first time ever, to develop an empirically-based analysis of the psychological functioning of women in the Mafia.

\section{CONCLUSIONS}

Despite its limitations, the present study could shed some light on the life of women who are involved with the Mafia, a neglected area of the research which can help in the understanding of the transmission of social values in the Mafia and similar crime networks.

In the Mafia world, individuals have little chance of developing a divergent thought process with respect to the family values and code of conduct (Lo Verso and Lo Coco 2004). Our study suggests that this continuity is warranted by a Mafia mother's traditional rearing of the child. Along this line, the identity of Mafia women is strongly affected by the culture of the family to which they belong. Mafia women must minimise or deny the criminal behaviours of their partners in order to protect their own emotional world as well as their identity as mothers and as the guardians of the family institution, even if this effort may cause them severe distress. Also, Mafia women often deal with the expectation of negative reactions and social judgment, and they report feelings of shame, loneliness and helplessness. Clinical and social work likely would help them in increasing their quality of life, i.e. their general wellbeing defined in terms of both health and happiness. Therefore, it can be crucial for society to use the emerging knowledge of the psychological condition of women involved with the Mafia for developing appropriate preventative and social measures to help these women in changing their ideals and beliefs related to the Mafia world: this would break the transmission of Mafia values thus hitting the Mafia organisation as a whole.

\section{CONFLICT OF INTERESTS}

None to be declared.

\section{REFERENCES}

Cottino, Amedeo. 1999. "Sicilian Cultures of Violence: The Interconnections between Organized Crime and Local Society." Crime, Law and Social Change 32(2):103-113. http://dx.doi.org/10.1023/A:1008389424861

Dean, Geoff, Ivan Fahsing, and Petter Gottschalk. 2010. Organized Crime. Oxford: Oxford University Press.

Dino, Alessandra. 2007. Women and the Mafia: Female Roles in Organized Crime structures. Miami, FL: Miami University Libraries.

Di Maria, Franco. 1997. "The 'Mafia feeling': A Transcultural Theme of Sicily." Group Analysis 30(3): 361-367. http://dx.doi.org/10.1177/0533316497303005

Di Maria, Franco, and Girolamo Lo Verso. 2007. Women in Mafia Organizations. Pp. 87-101 in Women and the Mafia. Female Roles in Organized Crime Structures, edited by G. Fiandaca. New York: Springer.

Fabj, Valeria. 1998. "Intolerance, Forgiveness, and Promise in the Rhetoric of Conversion: Italian Women Defy the Mafia." The Quarterly Journal of Speech 84(2):190-208.

http://dx.doi.org/10.1080/00335639809384213 
Falcone, Giovanni. 1992. Men of Honour: Truth about the Mafia. London, UK: Fourth Estate.

Fiore, Innocenzo (1997). Le radici inconsce dello psichismo mafioso [The Unconscious Roots of the Mafia]. Milan, IT: Franco Angeli.

Flocca, Francesco, and Serena Giunta. 2003. "Il femminile in Cosa Nostra [The Female World in Cosa Nostra]." Psychomedia. Rivista Telematica. Retrieved 18 November 2013 at http://www.psychomedia.it/pm/lifecycle/gender/floccagiunta.htm].

Giunta, Serena, Giuseppe Licari, and Girolamo Lo Verso. 2004. "La psiche mafiosa: stato dell'arte ed ipotesi per la ricerca [The Mafia Mind: Overview and Directions for Future Research]." Narrare il gruppo 1:21-32.

Hampton, James A., Alessia Passanisi, and Martin L. Jönsson. 2011. "The Modifier Effect and Property Mutability." Journal of Memory and Language 64(3):233-248. http://dx.doi.org/10.1016/j.jml.2010.12.001

Harris, Zellig S. 2002. The Background of Transformational and Metalanguage Analysis. Pp. 1-15 in The Legacy of Zellig Harris. Language and Information into 21st Century. Vol. I. Philosophy of Science, Syntax and Semantics, edited by E. B. Nevin. Amsterdam, NE: Jessica Benjamins.

Lancia, Franco. 2004. Strumenti per l'analisi dei testi. Introduzione all'uso di T-LAB [Instruments for Text-Analysis. An Introduction to the Use of T-LAB]. Milan, IT: Franco Angeli.

Lancia, Franco. 2012. "T-LAB 8.0 - User's Manual." Retrieved 18 November 2013 at http://www.tlab.it/it/bibliography.php

Lo Verso, Girolamo. 2003. The Psychological Assessment of Mafia Members (PAMM). A new measure for assessing the identity and mental representations of Mafia members. Unpublished manuscript, Department of Psychology, University of Palermo.

Lo Verso, Girolamo. 1998. La Mafia dentro. Psicologia e psicopatologia di un fondamentalismo [The Inner World of the Mafia. Psychology and Psychopathology of a Fundamentalism]. Milan, IT: Franco Angeli.
Lo Verso, Girolamo, and Gianluca Lo Coco. 2004. "Working with Patients Involved in the Mafia: Considerations from Italian Psychotherapy Experiences." Psychoanalytic Psychology 21(2): 171-182.

http://dx.doi.org/10.1037/0736-9735.21.2.171

Lo Verso, Girolamo, Gianluca Lo Coco, Saverio Mistretta, and Gabriella Zizzo. 1999. Come cambia la Mafia. Esperienze giudiziarie e psicoterapeutiche in un paese che cambia [The Mafia Changes. Legal and Psychotherapeutic Experiences in a Changing Country]. Milan, IT: Franco Angeli.

Lupo, Salvatore. 2009. The History of the Mafia. New York: Columbia University Press.

Nicaso, Antonio, and Lee LaMothe. 1995. Global Mafia: The New World Order of Organized Crime. Toronto, CAN: McMillan.

Passanisi, Alessia, Vito Leanza, and Gianluca Leanza. 2013. "The impact of sexually transmitted diseases on quality of life: application of three validated measures." Giornale Italiano di Ostetricia e Ginecologia 35(6):722-727.

Principato, Teresa, and Alessandra Dino. 1997. Mafia donna. Le vestali del sacro e dell'onore [Womanly Mafia. The Vestal Virgins of Sacred and Honor]. Palermo, IT: Flaccovio.

Roth, Mitchel P. 2010. Global Organized Crime. A Reference Handbook. Santa Barbara, CA: ABC-Clio.

Schimmenti, Adriano. 2012. "Unveiling the Hidden Self: Developmental Trauma and Pathological Shame." Psychodynamic Practice 18(2):181-194. http://dx.doi.org/10.1080/14753634.2012.664873

Schimmenti, Adriano, Chiara Caprì, Daniele La Barbera, and Vincenzo Caretti. 2014. "Mafia and Psychopathy". Criminal Behaviour and Mental Health. http://dx.doi.org/10.1002/cbm.1902

Schneider, Jane T., and Peter T. Schneider. 2003. Reversible Destiny: Mafia, Antimafia, and the Struggle for Palermo. Berkeley, CA: University of California Press.

Siebert, Renate (1996). Le donne, la Mafia [Women and the Mafia]. Milan, IT: II Saggiatore.

DOI: http://dx.doi.org/10.6000/1929-4409.2014.03.22

(C) 2014 Schimmenti et al.; Licensee Lifescience Global.

This is an open access article licensed under the terms of the Creative Commons Attribution Non-Commercial License (http://creativecommons.org/licenses/by-nc/3.0/) which permits unrestricted, non-commercial use, distribution and reproduction in any medium, provided the work is properly cited. 